\title{
Dental Educators' Perceptions of Educational Learning Domains
}

\author{
Eileen R. Hoskin, David C. Johnsen, Yun Saksena, Zsuzsa Horvath, Tracy de Peralta, Neal \\ Fleisher, Teresa A. Marshall, Cataldo Leone
}

Abstract: The aim of this study was to seek the views of a national sample of dental educators regarding the importance of learning domains in dental education, their defined outcomes of those domains, and their perceived effectiveness of their schools in guiding learning in those domains. The study defined the educational domains important for training future dentists as knowledge, technical skills, critical thinking, ethics, social responsibility, and interprofessional education/practice (IPE/IPP). A survey of members of the American Dental Education Association (ADEA) Special Interest Group on the Scholarship of Teaching and Learning was conducted in 2017. In addition to reporting their demographics, participants were asked to rate and rank the importance of each learning domain as well as answer open-ended questions. Of the 89 respondents (response rate 12.5\%), $31 \%$ were course directors, and $48 \%$ had been dental faculty members for more than ten years. Knowledge was ranked as the most important domain, followed by critical thinking, technical skills, clinical decision making, ethics, problem-solving, social responsibility, and finally IPE/IPP. When rating the absolute importance of these domains in the training of dental students, the respondents gave all but IPE/IPP and social responsibility the highest rating. Knowledge and technical skills were rated highest for respondents' confidence in defining student outcomes with similar high ratings for their confidence in guiding this learning. There was little consensus concerning a definition of critical thinking, and a third of the respondents were uncertain of specific learning outcomes for it. Participants expressed even less confidence in defining outcomes for ethics, IPE/IPP, and social responsibility. This baseline information will be used for a future in-depth study to aid in the development of strategies for articulating outcomes, guiding learning, and assessing performance in U.S. dental schools.

Eileen R. Hoskin is Director, Division of Operative Dentistry, Rutgers School of Dental Medicine; David C. Johnsen is Dean, University of Iowa College of Dentistry \& Dental Clinics; Yun Saksena is Associate Dean for Education and Associate Professor, Adult Restorative Dentistry, University of Nebraska Medical Center College of Dentistry; Zsuzsa Horvath is Assistant Professor and Director of Faculty Development, University of Pittsburgh School of Dental Medicine; Tracy de Peralta is Clinical Associate Professor, University of Michigan School of Dentistry; Neal Fleisher is Clinical Professor of General Dentistry, Director of Predoctoral Periodontology, and Director of Faculty Development, Henry M. Goldman School of Dental Medicine, Boston University; Teresa A. Marshall is Associate Professor, Department of Preventive and Community Dentistry, University of Iowa College of Dentistry \& Dental Clinics; and Cataldo Leone is Associate Dean for Academic Affairs and Professor of Periodontology, Henry M. Goldman School of Dental Medicine, Boston University. Direct correspondence to Dr. Eileen R. Hoskin, Division of Operative Dentistry, Rutgers School of Dental Medicine, 110 Bergen Street, Newark, NJ 07101-1709; 973-972-8622; hoskiner@sdm.rutgers.edu.

Keywords: dental education, academic performance, educational measurement, accreditation, assessment, critical thinking

Submitted for publication 2/15/18; accepted 6/29/18

doi: 10.21815/JDE.019.010

I $n$ dental education, developing definitions of learning domains, learning outcomes, and learning models and assessments is essential to guide student learning and assess student performance to determine competence. For this study, we defined the essential learning domains as follows: knowledge, technical skills, critical thinking, ethics, social responsibility, and interprofessional education/ practice (IPE/IPP). These domains are related to the areas in which graduating students should become competent as defined in the Commission on Dental Accreditation (CODA) Accreditation Standards and the American Dental Education Association (ADEA) Competencies for the New General Dentist. ${ }^{1,2}$

Johnsen et al.'s 2011 article described a matrix approach to learning in dental education. ${ }^{3}$ In compar-

ing domains, Johnsen et al. suggested similarities in the way knowledge and technical skill are defined, guided in learning, and assessed. The critical thinking domain is known to be important for the dentist, yet models have not been published for actually defining learning outcomes for it. Attaining competence in critical thinking does not fit neatly into courses or departments, and it crosses curriculum years. ${ }^{4-8}$

In Schneider et al.'s study, faculty members and students at one U.S. dental school rated all learning domains as being high in importance. ${ }^{9}$ They rated knowledge and technical skills highly for level of confidence in their school's methods of teaching, assessing, and counting toward competence. Interestingly, however, they gave lower confidence ratings to other domains such as critical thinking and ethics 
for teaching, assessing, and counting toward competence. Johnsen et al. noted that the CODA standards focus on learning outcomes, but without a body of scholarship as a source, and provide no prototype or reference to calibrate CODA site visitors or to train educators/students. ${ }^{10}$ In addition, Thistlethwaite and Moran noted a "wholesale lack of consistency in defining and describing learning outcomes" for IPE/ IPP. ${ }^{11}$ As a result, at the same time dental education endorses learning domains as essential for the training of competent dentists, we as educators may struggle to define and assess student outcomes in these areas.

With this obstacle in mind, the aim of our study was to seek the views of a national sample of dental educators regarding the importance of learning domains in dental education, their defined outcomes of those domains, and their perceived effectiveness of their schools in guiding learning in those domains. We also sought further information on these educators' perceptions of teaching and assessing critical thinking, one of the learning domains. The ability to explicitly define learning outcomes to guide learning and assess performance is important to improve the learning experience in dental education.

\section{Methods}

The survey instrument and its mode of distribution were approved by the Rutgers School of Dental Medicine/Newark Health Sciences Institutional Review Board (Study ID: Pro 20170000641). Those invited to participate were members of the ADEA Special Interest Group (SIG) on the Scholarship of Teaching and Learning (SoTL). We chose this group because, while not a comprehensive or definable national cohort, we know anecdotally that many U.S. dental schools are represented among its members, and the ADEA members who join this SIG can be assumed to have an interest in teaching and learning. We distributed the survey to members of the SIG via its listserv, and the survey was open for responses from September 15 to October 25, 2017. The survey was sent once, with no reminders.

Our literature review found no published validated instrument for a faculty survey of the importance of learning domains in dental education. Therefore, the project team of seven faculty members focused on educational methods developed a questionnaire specifically for the study. After reviewing the CODA standards and competency statements and formulating goals, the group developed, reviewed, and agreed on a survey instrument.
The survey consisted of 14 questions in the form of yes/no, multiple-choice, multiple-answer, rating scale, rank order, and open-ended questions. The closed-end questions asked about participants' teaching roles and experience and asked them to rank the importance of educational domains in training competent dentists, to rate their own level of confidence in defining learning outcome(s) for the educational domains, and to rate their level of confidence that their schools adequately guided student learning in these domains. The open-ended questions were all in the critical thinking domain: Where does critical thinking fit into your dental school's curriculum (please state whether it is a course unto itself or is embedded in other course/s)? If possible, please share the learning outcome for the critical thinking domain. If a learning outcome for critical thinking has been defined, how is your institution assessing students' performance toward achievement of this outcome? How would you define critical thinking? Could your school improve on its teaching of critical thinking skills; if so, how?

Participants provided consent by completing the survey questions. No compensation for participation was provided, and respondents were offered the opportunity to review the research findings upon completion. Surveys were sent and received anonymously since ADEA's listservs do not display recipients by name and the responses were submitted with no method of identification. When we emailed the survey to the SoTL SIG listserv, we received this automatic response: "Your email was successfully sent to 711 members of the SoTL listserv." Results were collected using Qualtrics (Provo, UT, USA).

\section{Results}

At the time of the survey, the SoTL SIG listserv had 711 members. Of those, 89 members responded for a $12.5 \%$ response rate. A little less than half $(46 \%)$ of the respondents reported teaching predoctoral dental students. The largest group of respondents (48\%) had more than ten years' experience in dental education, and $67 \%$ had been teaching at least six years. The most common responses to the question about the respondents' role in their institution were course director (31.1\%) and clinical faculty (29.7\%); the remaining respondents were in administration (e.g., dean, department chair) or on the preclinical faculty. One-third of the respondents $(35.5 \%)$ reported having a master's or doctoral degree in education. 


\section{Responses on Closed-End Items}

Respondents were asked to rank the importance of each listed educational domain on a scale from $0=$ highest to $8=$ lowest (Figure 1). Weighted averages and individual rankings showed that knowledge was ranked as the most important domain, and critical thinking was second. IPE/IPP and social responsibility were ranked the lowest. Respondents were also asked to rank each domain's importance in the creation of a competent dentist on a scale from $1=$ not very important to $5=$ very important (Table 1 ). Respondents who chose very important and important totaled over $50 \%$ for all domains. Nearly all domains received high ratings, with more than $65 \%$ of respondents giving a 5 rating to all except IPE/ IPP and social responsibility. The responses for the domains were distributed primarily among 5,4 , and 3. More respondents gave a lower rating for IPE/ IPP $(1,2$, or 3$)$ than knowledge, and the difference was statistically significant $\left(X^{2}=34.4 ; p<0.01\right)$. The difference in the number of 5 ratings between knowledge and IPE/IPP was also statistically significant $\left(\mathrm{X}^{2}=39.3 ; \mathrm{p}<0.01\right)$. The highest level (rating 5$)$ was most frequently assigned to knowledge, technical skills, critical thinking, ethics, clinical decision making, and problem-solving.

When respondents were asked to rate their level of confidence in defining the learning outcomes for the domains on a scale from $1=$ not very confident

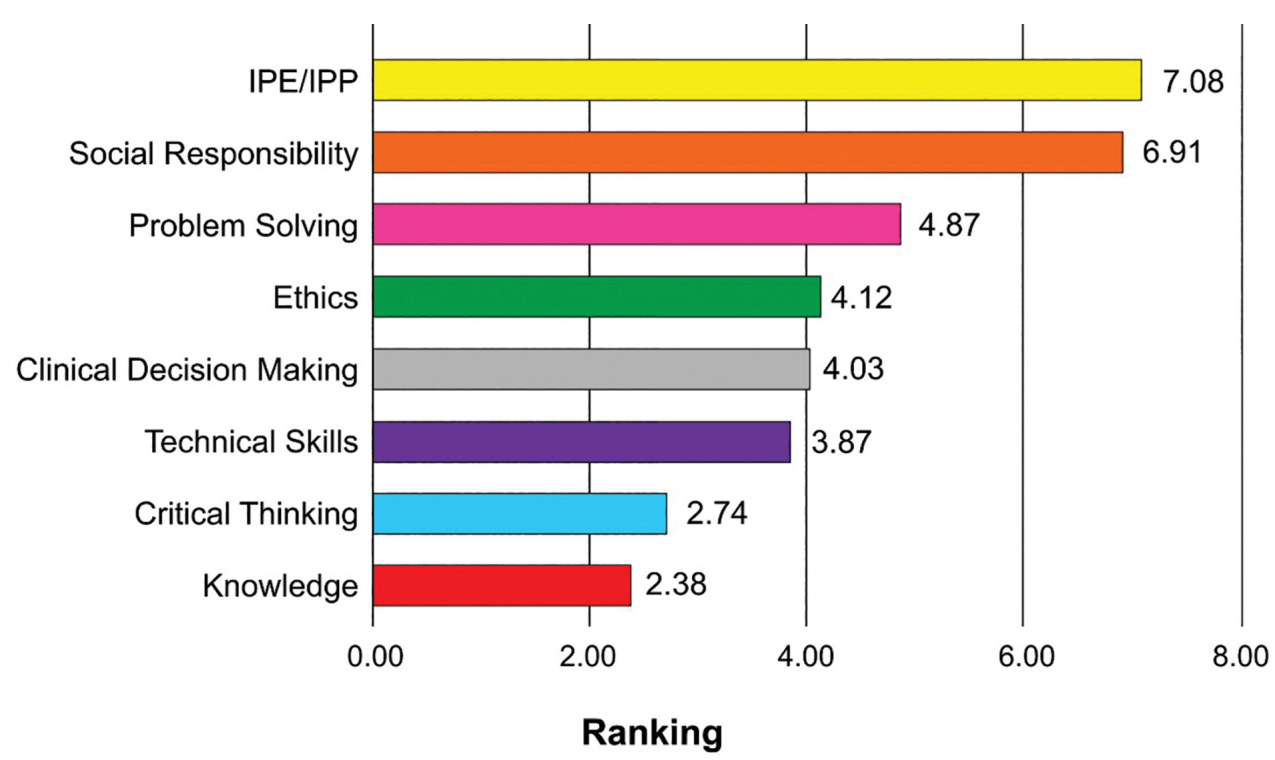

Figure 1. Respondents' mean ranking of importance of eight specified educational domains

Note: Respondents ranked the importance of each educational domain on a scale from $0=$ highest to $8=$ lowest.

Table 1. Respondents' rating of importance of each educational domain for creation of a competent dentist

\begin{tabular}{|c|c|c|c|c|c|c|c|c|c|c|c|}
\hline Domain & $\begin{array}{r}5 \\
\text { Percent }\end{array}$ & $\mathrm{n}$ & $\begin{array}{r}4 \\
\text { Percent }\end{array}$ & $\mathrm{n}$ & $\begin{array}{r}3 \\
\text { Percent }\end{array}$ & $\mathrm{n}$ & $\begin{array}{r}2 \\
\text { Percent }\end{array}$ & $\mathrm{n}$ & $\begin{array}{r}1 \\
\text { Percent }\end{array}$ & $\mathrm{n}$ & Total \\
\hline Knowledge & $74.7 \%$ & 62 & $21.7 \%$ & 18 & 0 & 0 & 0 & 0 & $3.6 \%$ & 3 & 83 \\
\hline Technical skills & $65.5 \%$ & 55 & $25.0 \%$ & 21 & $4.8 \%$ & 4 & $1.2 \%$ & 1 & $3.6 \%$ & 3 & 84 \\
\hline Critical thinking & $81.7 \%$ & 67 & $12.2 \%$ & 10 & $2.4 \%$ & 2 & 0 & 0 & $3.7 \%$ & 3 & 82 \\
\hline Ethics & $76.2 \%$ & 64 & $14.3 \%$ & 12 & $3.6 \%$ & 3 & $2.4 \%$ & 2 & $3.6 \%$ & 3 & 84 \\
\hline Interprofessional education/practice & $26.2 \%$ & 22 & $32.1 \%$ & 27 & $28.6 \%$ & 24 & $8.3 \%$ & 7 & $4.8 \%$ & 4 & 84 \\
\hline Social responsibility & $32.1 \%$ & 27 & $34.5 \%$ & 29 & $22.6 \%$ & 19 & $6.0 \%$ & 5 & $4.8 \%$ & 4 & 84 \\
\hline Clinical decision making & $83.1 \%$ & 69 & $13.3 \%$ & 11 & 0 & 0 & 0 & 0 & $3.6 \%$ & 3 & 83 \\
\hline Problem-solving & $77.4 \%$ & 65 & $15.5 \%$ & 13 & $2.4 \%$ & 2 & 0 & 0 & $4.8 \%$ & 4 & 84 \\
\hline
\end{tabular}

Note: Responses were on a scale from $1=$ not very important to $3=$ not sure to $5=$ very important. A varying number of respondents $(\mathrm{n}=82$ to $\mathrm{n}=84$ ) ranked each item. 
to $5=$ very confident, the domains received ratings mostly of 3, 4, and 5 (Table 2). More than $75 \%$ of the respondents gave their confidence in defining knowledge and technical skills outcomes a 5 rating. The domains critical thinking and ethics had responses nearly identical to each other, with the highest rating a 5 and ratings 4 and 3 somewhat equally distributed. This finding differs significantly from knowledge and technical skills in the number of responses with a 5 rating. More respondents gave a 5 rating to their confidence regarding knowledge than to critical thinking, and the difference was statistically significant $\left(\mathrm{X}^{2}=29.1 ; \mathrm{p}<0.01\right)$. The domains IPE/IPP and social responsibility had a wider distribution to include a higher number of 3 ratings. Fewer respondents gave a confidence rating of 5 to IPE/IPP and social responsibility than to critical thinking and ethics $\left(\mathrm{X}^{2}=9.97 ; \mathrm{p}<0.01\right)$. More respondents gave IPE/IPP a lower confidence rating ( 2 or 3 ) than they did to critical thinking, and the difference was statistically significant $\left(X^{2}=7.5 ; p<0.01\right)$.

Respondents were also asked to rate their level of confidence that their institutions adequately guided student learning in these educational domains on a scale from $1=$ not very confident to $5=$ very confident (Table 3). More respondents gave knowledge a confidence rating of 5 than gave that ranking to critical thinking, and the difference was statistically significant $\left(X^{2}=19.4 ; p<0.01\right)$. More respondents gave critical thinking a confidence rating of 4 or 5 than gave that rating to IPE/IPP, and the difference was statistically significant $\left(X^{2}=4.3 ; p<0.05\right)$. IPE/IPP and social responsibility received lower ratings than the other domains for the questions on its importance, confidence in defining the outcome, and confidence in the institution for guiding the learning. Results for respondents' confidence in the institution for guiding the learning were strikingly similar to the results for their own confidence in defining the outcome.

\section{Responses About Critical Thinking}

No pattern was found regarding non-respondents to the questions about critical thinking. On the question "Where does critical thinking fit into your school's curriculum? (Please state whether it is a course unto itself or is embedded in other course/s.)," 55 of the 63 respondents $(87 \%)$ to this question

Table 2. Respondents' level of confidence in defining learning outcomes for each domain

\begin{tabular}{|c|c|c|c|c|c|c|c|c|c|c|c|}
\hline Domain & $\begin{array}{r}5 \\
\text { Percent }\end{array}$ & $\mathrm{n}$ & $\begin{array}{r}4 \\
\text { Percent }\end{array}$ & $\mathrm{n}$ & $\begin{array}{r}3 \\
\text { Percent }\end{array}$ & $\mathrm{n}$ & $\begin{array}{r}2 \\
\text { Percent }\end{array}$ & $\mathrm{n}$ & $\begin{array}{r}1 \\
\text { Percent }\end{array}$ & $\mathrm{n}$ & Total \\
\hline Knowledge & $74.7 \%$ & 62 & $21.7 \%$ & 18 & 0 & 0 & 0 & 0 & $3.6 \%$ & 3 & 83 \\
\hline Technical skills & $65.5 \%$ & 55 & $25.0 \%$ & 21 & $4.8 \%$ & 4 & $1.2 \%$ & 1 & $3.6 \%$ & 3 & 84 \\
\hline Critical thinking & $81.7 \%$ & 67 & $12.2 \%$ & 10 & $2.4 \%$ & 2 & 0 & 0 & $3.7 \%$ & 3 & 82 \\
\hline Ethics & $76.2 \%$ & 64 & $14.3 \%$ & 12 & $3.6 \%$ & 3 & $2.4 \%$ & 2 & $3.6 \%$ & 3 & 84 \\
\hline Interprofessional education/practice & $26.2 \%$ & 22 & $32.1 \%$ & 27 & $28.6 \%$ & 24 & $8.3 \%$ & 7 & $4.8 \%$ & 4 & 84 \\
\hline Social responsibility & $32.1 \%$ & 27 & $34.5 \%$ & 29 & $22.6 \%$ & 19 & $6.0 \%$ & 5 & $4.8 \%$ & 4 & 84 \\
\hline Clinical decision making & $83.1 \%$ & 69 & $13.3 \%$ & 11 & 0 & 0 & 0 & 0 & $3.6 \%$ & 3 & 83 \\
\hline Problem solving & $77.4 \%$ & 65 & $15.5 \%$ & 13 & $2.4 \%$ & 2 & 0 & 0 & $4.8 \%$ & 4 & 84 \\
\hline
\end{tabular}

Note: Responses were on a scale from $1=$ not very confident to $3=$ not sure to $5=$ very confident. A varying number of respondents ( $\mathrm{n}=82$ to $\mathrm{n}=84$ ) ranked each item.

Table 3. Respondents' level of confidence that their institution has adequately guided student learning in each domain

\begin{tabular}{|c|c|c|c|c|c|c|c|c|c|c|c|}
\hline Domain & $\begin{array}{r}5 \\
\text { Percent }\end{array}$ & $\mathrm{n}$ & $\begin{array}{r}4 \\
\text { Percent }\end{array}$ & $\mathrm{n}$ & $\begin{array}{r}3 \\
\text { Percent }\end{array}$ & $n$ & $\begin{array}{r}2 \\
\text { Percent }\end{array}$ & $\mathrm{n}$ & $\begin{array}{r}1 \\
\text { Percent }\end{array}$ & $\mathrm{n}$ & Total \\
\hline Knowledge & $75.9 \%$ & 63 & $19.3 \%$ & 16 & $2.4 \%$ & 2 & 0 & 0 & $2.4 \%$ & 2 & 83 \\
\hline Techni & $76.8 \%$ & 63 & $12.2 \%$ & 10 & $7.3 \%$ & 6 & 0 & 0 & $3.7 \%$ & 3 & 82 \\
\hline Critical thinking & $34.2 \%$ & 28 & $31.7 \%$ & 26 & $26.8 \%$ & 22 & $4.9 \%$ & 4 & $2.4 \%$ & 2 & 82 \\
\hline Ethics & $34.2 \%$ & 28 & $28.1 \%$ & 23 & $29.3 \%$ & 24 & $7.3 \%$ & 6 & $1.2 \%$ & 1 & 82 \\
\hline sional education/practice & $13.3 \%$ & 11 & $31.3 \%$ & 26 & $41.0 \%$ & 34 & $14.5 \%$ & 12 & 0 & 0 & 83 \\
\hline Social responsibility & $15.7 \%$ & 13 & $25.3 \%$ & 21 & $37.4 \%$ & 31 & $18.1 \%$ & 15 & $3.6 \%$ & 3 & 83 \\
\hline Clinical decision making & $49.4 \%$ & 40 & $35.8 \%$ & 29 & $11.1 \%$ & 9 & $1.2 \%$ & 1 & $2.5 \%$ & 2 & 81 \\
\hline Problem solving & $40.2 \%$ & 33 & $39.0 \%$ & 32 & $15.9 \%$ & 13 & $2.4 \%$ & 2 & $2.4 \%$ & 2 & 82 \\
\hline
\end{tabular}

Note: Responses were on a scale from $1=$ not very confident to $3=$ not sure to $5=$ very confident. $A$ varying number of respondents ( $\mathrm{n}=81$ to $\mathrm{n}=83$ ) ranked each item. 
reported that critical thinking was embedded in other course/s. Five (8\%) stated that it was a course or a combination of courses, and three $(5 \%)$ stated that they did not know. The combined results thus show that critical thinking was being taught in $95 \%$ of the respondents' institutions.

For the other open-ended questions, we present the results in order starting with those with the most responses and the most cohesive pattern of responses to, last, those with the fewest responses and least cohesive pattern of responses. Response categories were delineated and categorized after we viewed the survey results. Two authors (DJ and EH) individually grouped responses and then reached a consensus on placement of results into categories. For all open-ended questions except \#13 (provide a definition for critical thinking), respondents reported an array of approaches to defining, assessing, and recommending improvements.

The question "How would you define critical thinking?" had the most responses $(n=52 ; 58 \%$ of total respondents) and the most cohesive pattern of answers. Many responses were detailed and descriptive. A variation of a technique previously described to understand faculty members' perspectives on critical thinking and evidence-based dentistry ${ }^{12}$ was used to categorize responses to the question asking for a definition of critical thinking. Of the 52 responses, 47 $(90 \%)$ used a verb reflecting thinking or a descriptor reflecting thinking. Many responses used more than one verb. For an initial analysis, the first verb in each response was recorded. Of the 47 responses with a verb reflecting thinking, 23 verbs were recorded. The most common was "analyze" as the first verb in 12 responses, "apply" in six responses, and "evaluate" in three responses. No other verb had more than two responses. Higher order verbs of complexity and specificity noted in Bloom's taxonomy ${ }^{13}$ were common on this list. The other verbs and number of times each was used were as follows: two uses each for "assess," "formulate," "interpret," "identify possibilities," "problem solve," "thought process," and "weigh"; and one use each for "combine," "conceptualize," "cognizance," "conclude," "discern," "discriminate," "design," "diagnose," "incorporate," "integrate," "perform tasks," "reason," "reflect," and "synthesize." Other words used as the second verb were "integrate," "judge," "options," and "question."

The question "Could your school improve teaching of critical thinking skills; if so, how?" had the next highest number of responses with 50 (56\% of total respondents) and the next most co- hesive pattern of responses. All of the respondents answered that they felt their school could improve upon the teaching of critical thinking skills, and their responses suggest they were passionate about their answers. The ideas for methods to improve varied. Unlike the question that asked respondents to define the learning outcome for critical thinking on which nine were uncertain, this question had only three responses $(6 \%)$ that expressed uncertainty about how their school could improve the teaching of critical thinking-likely because some respondents chose not to answer this question if they did not have a specific idea for improvement. Although respondents provided suggestions for improving the teaching of critical thinking, some noted uncertainty concerning the learning outcome and assessment necessary. Fifteen respondents (30\%) offered a specific activity suggestion such as "I believe that we do not place enough emphasis on literature review and study." Eleven respondents (22\%) gave a response that we categorized as "integration into a course." Examples of this response were "encourage critical thinking with our D3s and D4s working together with patient care" or "including it as a separate lecture as opposed to embedding it." Twenty-one respondents (42\%) were very supportive of the need for improvement but had no specific recommendations.

The questions on assessing performance and defining critical thinking had the fewest responses (33 and 28, respectively) and the least cohesive patterns of responses. On the question "How is your school assessing students' performance toward achievement of the learning outcome for critical thinking?," there were 33 responses (37\% of total respondents). We grouped eight responses (24\%) in the category of subjective or generally observational assessment. Examples included "assessed daily in clinical interactions" or "written case-based exercise(s), discussions in small groups." Three respondents (9\%) listed general tests that were vague such as "a variety of tools (written and verbal) that encourage student self-reflection." Nine others (28\%) were slightly more specific, mentioning a type of assessment such as an objective structured clinical exam (OSCE) or a simulation exercise. Five respondents (15\%) listed a specific type of skillset as an assessment instrument such as "a specific course that requires students to present the latest literature on a topic" or "a rubric for a treatment plan." Finally, eight (24\%) were uncertain with answers like "I am not aware of specifics."

The request to "share the outcome that has been defined for critical thinking" had the fewest responses 
and the most diffuse pattern of responses with few definitive comments. Only 28 individuals (31\%) responded - the lowest response for any item. This small number is unlikely to be attributable to survey fatigue in that the proceeding questions that were also open-ended received between 33 and 50 responses (37\%-56\%). Responses were evenly divided among non-specific outcomes, exercises that emulate the activity of a practicing dentist, and uncertain. Nine respondents (32\%) reported a non-specific outcome for critical thinking such as listing the competency statements for the domain. Another nine (32\%) were more specific in describing an exercise that would emulate the activity of a practicing dentist such as the thought processes involved in planning treatment for a new patient. One participant responded, "In one course, we have a case study, and [students] identify issues related to this," while another noted, "a certain number identified determines critical thinking." Two respondents in this group listed non-specific assessments such as an OSCE. The remaining nine (32\%) responses were categorized as uncertain with answers like "developing it."

\section{Discussion}

We interpreted the high ratings respondents gave to knowledge and technical skills to indicate high levels of importance and confidence in teaching these learning domains relative to the other domains in all categories: absolute importance, relative importance, individual (faculty) confidence in defining outcomes, and institutional confidence in guiding learning. These respondents considered the domains of knowledge, technical skills, critical thinking, and ethics to be of highest importance.

The results showed a wide spectrum of confidence levels in defining learning outcomes for critical thinking, ethics, IPE/IPP, and social responsibility. Further, we interpreted the spectrum of definitions for critical thinking as indicating a limited consensus on a definition. These findings are consistent with the results of a previous survey at one school. ${ }^{9}$ Our respondents had a lower level of confidence in defining the outcomes for IPE/IPP and social responsibility than for critical thinking and ethics. It may also be of importance that IPE/IPP and social responsibility received lower ratings for importance and that an association existed between the respondents' level of understanding and their level of perceived importance.
For all domains, results for respondents' confidence in the institution guiding learning were strikingly similar to the results for confidence of the individual to define the learning outcome. One interpretation of this result is that there is a conscious connection between respondents' views and the learning activities at their school. The domains of critical thinking, clinical decision making, and problem-solving appeared to occupy similar spaces in the minds of these respondents as indicated by similar ratings on the three questions about absolute importance. Despite the efforts of national organizations to emphasize the importance of IPE ${ }^{14,15}$ and social responsibility, our results suggest that dental faculty members may lack a clear understanding of learning outcomes in these areas, without which guided learning and performance assessment are challenging.

\section{Open-Ended Questions}

A high level of commitment to teaching critical thinking was found among these respondents' institutions, with $95 \%$ of those who answered this question reporting that critical thinking was being taught in some way in their curricula. The high number of and more definitive responses to the question seeking a definition of critical thinking may suggest that the learning outcome for the domain is more difficult to articulate than the definition. These respondents perceived critical thinking in active terms as indicated by their use of verbs reflecting thinking in the definitions provided. While a single definition did not emerge, these respondents' listing of verbs reflecting thinking indicated widespread understanding that critical thinking involves an active process of thought, as suggested by Johnsen. ${ }^{16}$ Paul and Elder defined critical thinking as "the art of analyzing one's thought process with the intent of improving it." ${ }^{17}$ However, their definition was not pervasive in responses to the survey.

These respondents reported a variety of approaches to assessing critical thinking, perhaps unsurprising considering the small number of responses to the question asking for definitions of the outcome of critical thinking. It is difficult to assess performance without an intended outcome. Possibly following the concept that the validity of the assessment is associated with direct emulation of the intended activity, ${ }^{16,18,19}$ these respondents may be expressing an "I'll know it when I see it" approach to assessing critical thinking. However, the respondents reported that improvement in education for critical thinking 
was a priority. Some specific ideas for improvement were provided by 17 respondents (34\%) who named a specific activity.

Some limitations of this analysis should be noted. The most important limitation results from the very low response rate $(12.5 \%)$, even in this self-selected group of dental educators who were presumed to have a particular interest in teaching and learning. Furthermore, only $46 \%$ of the respondents said they teach predoctoral students, who are the target group for the learning domains being assessed. These low rates mean the results cannot be generalized to predoctoral dental educators in general or even to all members of the SoTL SIG. Since the responses were anonymous, there was also no way to determine the number of schools represented by respondents; thus, it is impossible to determine how widespread the perceptions reported are across U.S. dental schools. The results were also limited because data from single rating questions are more reproducible than data from open-ended questions that were classified by the authors. While we chose this group for the study based on the assumption that members of the SoTL SIG were educators with an enhanced interest in analyzing teaching and learning with the intent of improving upon it, we could not assess the accuracy of that assumption or determine the depth and extent of interest in critical thinking among the SIG's members. Finally, the survey was developed for this study and was not pilot-tested or validated; further research is needed to refine the instrument and to validate the survey.

\section{Critical Thinking Culture of Inquiry}

Despite these limitations, this study was a first effort to acquire the collective view of a national cohort of dental educators with a presumed interest in the scholarship of teaching and learning regarding their insights into the absolute and comparative importance of learning domains in dental education. The culture of inquiry around critical thinking in dental education has expanded in the last few decades and is reflected in the results of our survey. Many methodologies have been used to assess indicators of critical thinking, such as short-answer exams, OSCEs, algorithms, and creative multiple-choice tests. An emerging approach to critical thinking follows concepts in the education literature seeking emulation of the intended activity: the more direct the emulation, the greater the validity of the assessment. ${ }^{19}$ The outcome is the thought process or skillset of the expert derived succinctly enough for application by the novice - an approach reported in a peer-reviewed article about treatment planning, literature critique and review, caries risk, geriatric risk, technology decision making, IPE/IPP, and situation analysis/ reflections. ${ }^{18}$ Our results were also consistent with the findings from von Bergmann et al.'s survey of participants in a problem-based learning conference who perceived that the characteristics of a good dentist included ethics, technical, critical thinking, and knowledge and reported "variations in perceived purpose of teaching dental students ... [and] . . . varying concepts of what a good dentist looks like." ${ }^{20}$ A concluding recommendation of their study was to "embrace learning as an ongoing process in which uncertainty exists."

For the learning domains of knowledge and technical, the participants in our study were confident in articulating the learning outcome, guiding the learning, and assessing the performance. Thus, little commentary was provided on knowledge and technical. For critical thinking, an area in which our study's participants were less confident in articulating the outcome, guiding learning, and assessing performance, previous studies have provided a starting point for assessment in which multiplechoice tests, OSCEs, and algorithms were used as indicators of critical thinking. ${ }^{21-23}$ To articulate the outcome, guide learning, and assess performance in critical thinking, an emerging approach follows concepts in the education literature calling for the following: engaging students in multiple experiences reflecting critical thinking; emulating the intended activity with the more direct the emulation, the greater the validity; gaining agreement of experts on the content, application, and assessment for reliability; using the same instrument to guide learning and assess performance; and including alternatives, biases, and self-assessment. ${ }^{16,19,24}$ With the emulation approach, learning guidance and performance assessment occur in the act of critical thinking. The emulation approach includes the assumption that, to meaningfully guide learning and assess performance, the educator must first know what the student is to do. An additional perspective has used the concept of novice to expert, in which the thought process of the expert is derived succinctly enough for application by the novice. ${ }^{25}$ Ethics is similar to critical thinking in the lesser level of confidence to define the outcome, guide learning, and assess performance. While much has been done for ethics, the learning outcomes beyond the knowledge of ethical principles are in the 
early stages, with work to be done to guide learning and assess performance..$^{26,27}$ Defining learning outcomes for ethics in the clinical situation should be an agenda item for educators. While IPE and IPP have received considerable attention from national health organizations, the participants in our study had little confidence (along with social responsibility, the least confident of the domains) in articulating the outcomes, guiding learning, and assessing performance. A next step for educators would be to collectively articulate learning outcomes for IPE/IPP, which Thistlethwaite and Moran suggested in 2010 had a "wholesale lack of consistency."11 Defining learning outcomes for IPE/IPP is more within reach than those for social responsibility.

Finally, the SoTL SIG has the potential to provide insight into the teaching habits and philosophies of actively engaged and experienced dental educators. This survey is only one area to apply the expertise of this experienced and committed group.

\section{Conclusion}

Although our survey had a low response rate, its findings supported the primacy of the learning domains of knowledge and technical skills for dental educators both in importance (both relative to other domains and absolute) and in faculty members' confidence in defining outcomes. The survey results also support the importance of critical thinking and ethics to the respondents, but showed they had less confidence in defining outcomes for these domains. We interpreted these results as indicating a wide spectrum of certainty regarding defining outcomes for critical thinking, ethics, IPE/IPP, and social responsibility. Further, the spectrum of definitions provided for critical thinking suggests limited consensus on a definition. Paths forward may include the following: for critical thinking, gain consensus on a definition, and articulate outcomes; for IPE/IPP, ethics, and social responsibility, articulate the outcomes, and find ways to expand the view of dental care beyond the teeth. For critical thinking specifically, we recommend development of outcomes to guide student learning toward what the dental educator wants the student to do to emulate the activity of the practicing dentist.

\section{Acknowledgments}

We thank Rob Cline and Michael Tilley for manuscript assistance and Laura Felleman and Pat Conroy for the graphics.

\section{REFERENCES}

1. Commission on Dental Accreditation. Accreditation standards for dental education programs. 2018. At: www. ada.org/ /media/CODA/Files/pde.pdf?la=en. Accessed 15 Nov. 2018.

2. American Dental Education Association. ADEA competencies for the new general dentist. J Dent Educ 2017;81(7):844-7.

3. Johnsen DC, Marshall TA, Finkelstein MW, et al. A model of student learning: a matrix of educational outcomes versus methodologies. J Dent Educ 2011;75(2):160-8.

4. Baron J. Thinking and deciding. 4th ed. Cambridge, UK: Cambridge University Press, 2008.

5. Bao L, Cai T, Koenig K, et al. Physics, learning, and scientific reasoning. Science 2009;323(5914):586-7.

6. Singer SR, Nielsen NR, Schweingruber HA. Disciplinebased education research: understanding and improving learning in undergraduate science and engineering. Washington, DC: National Academies Press, 2012.

7. Johnsen DC, Glick M. The future is not ours to see, but there is always critical thinking. J Am Dent Assoc 2016;149(9):693-5.

8. Bransford JD, Brown AL, Cocking RR. Learning, from speculation to science: how experts differ from novices. In: Commission on Behavioral and Social Sciences Education, National Research Council. How people learn: brain, mind, experience, and school. Washington, DC: National Academy Press, 2000:3-27,31-50.

9. Schneider GB, Cunningham-Ford MA, Johnsen DC, et al. Outcomes mapping: a method for dental schools to coordinate learning and assessment based on desired characteristics of a graduate. J Dent Educ 2014;78(9):1268-78.

10. Johnsen DC, Williams JN, Baughman PG, et al. New dental accreditation standard on critical thinking: a call for learning models, outcomes, assessments. J Dent Educ 2015;79(10):1137-9.

11. Thistlethwaite J, Moran M. Learning outcomes for interprofessional education (IPE): literature review and synthesis. J Interprof Educ 2010;24(5):503-13.

12. Marshall TA, Straub-Morarend CL, Qian F, Finkelstein MW. Perceptions and practices of dental school faculty regarding evidence-based dentistry. J Dent Educ 2013;77(2):146-51.

13. Benjamin BS. Taxonomy of educational objectives, handbook: vol. 1, cognitive domain. New York: David McKay, 1956.

14. Interprofessional Education Collaborative. 2017. At: ipecollaborative.org/. Accessed 10 June 2017.

15. D’Amour D, Ferrada-Videla M, Rodriguez LSM, et al. The conceptual basis for interprofessional collaboration: core concepts and theoretical framework. J Interprof Care 2005;19(Suppl 1):116-31.

16. Johnsen DC. Critical thinking: focal point for a culture of inquiry. In: Boyle C, ed. Student learning: improving practice. Hauppauge, NY: Nova Science, 2013:151-70.

17. Paul R, Elder L. Critical thinking tools for changing your learning and your life. 2nd ed. Upper Saddle River, NJ: Pearson Prentice Hall, 2006.

18. Marshall TA, Marchini L, Cowen H, et al. Critical thinking theory to practice: using the expert's thought process as guide to learning and assessment. J Dent Educ 2017;81(8):978-85. 
19. Lane S, Stone CA. Performance assessment. In: Brennan RL, National Council on Measurement in Education, American Council on Education, eds. Educational measurement. 4th ed. Westport, CT: Praeger, 2006:1-112.

20. von Bergmann HC, Walker J, Dalrymple KR, Shuler CF. Dental faculty members' pedagogic beliefs and curriculum aims in problem-based learning: an exploratory study. $\mathrm{J}$ Dent Educ 2017;81(6):937-47.

21. Sastre-Fullana P. Advanced practice nursing competency assessment instrumentation (APNCAI): clinimetric validation. BMJ Open 2017; 7:e013659.

22. Damodaran A, Shulruf B, Jones P. Trust and risk: a model for medical education. Med Educ 2017;51:892-902.

23. Plack M, Goldman E, Scott A. Systems thinking and systems-based practice across the health professions: an inquiry into definitions, teaching practices, and assessment. Teach Learn Med 2017;30(3):242-54.
24. Johnsen DC, Lipp MJ, Finkelstein MW, CunninghamFord MA. Guiding dental student learning and assessing performance in critical thinking with analysis of emerging strategies. J Dent Educ 2012;76(12):1548-58.

25. Benner P. From novice to expert. Menlo Park, CA: Addison Wesley, 2001.

26. Sharp HM, Kuthy RA, Heller KE. Ethical dilemmas reported by fourth-year dental students. J Dent Educ 2005;69(10):1116-21.

27. Sharp HM, Kuthy RA. What do dental students learn in an ethics course? An analysis of student-reported learning outcomes. J Dent Educ 2008;72(12):1450-7. 